\title{
Prevalence and spectrum of GJA5 mutations associated with lone atrial fibrillation
}

\author{
HAI-FENG SHI $^{1}$, JIE-FU YANG ${ }^{1}$, QIAN WANG ${ }^{2}$, RUO-GU LI ${ }^{2}$, YING-JIA XU ${ }^{2}$, XIN-KAI QU ${ }^{2}$, \\ WEI-YI FANG ${ }^{2}, \mathrm{XU}_{\mathrm{LIU}}^{2}$ and YI-QING YANG ${ }^{2}$ \\ ${ }^{1}$ Department of Cardiology, Beijing Hospital, Beijing 100730; ${ }^{2}$ Department of Cardiology and Cardiovascular Research, \\ Shanghai Chest Hospital, Shanghai Jiaotong University School of Medicine, Shanghai 200030, P.R. China
}

Received October 10, 2012; Accepted December 19, 2012

DOI: $10.3892 / \mathrm{mmr} .2012 .1252$

\begin{abstract}
Atrial fibrillation (AF) is the most common form of cardiac arrhythmia observed in clinical practice and a major contributor to cardiovascular morbidity and mortality. Accumulating evidence indicates a substantial genetic basis for AF. However, AF is genetically heterogeneous and the hereditary components responsible for AF remain to be identified in the majority of patients. The cardiac gap junction protein $\alpha 5$ (GJA5) is specifically expressed in atrial myocytes and is associated with the coordinated electrical activation of the atria, providing a rationale to screen GJA5 as a logical candidate gene for AF. A cohort of 310 unrelated patients with lone AF and their available relatives were included in this study. A group of 200 unrelated healthy individuals matched for age, gender and race were also included as controls. The entire coding region and splice sites of the GJA5 gene were initially sequenced in 310 unrelated AF patients. The relatives of mutation carriers and 200 controls were subsequently genotyped for the presence of identified mutations. As a result, 4 novel heterozygous GJA5 mutations, p.K107R, p.L223M, p.Q236H and p.I257L, were identified in 4 of 310 unrelated AF patients, respectively, with a prevalence of $\sim 1.29 \%$. Genetic analysis of the carriers' families showed that in each family the missense mutation was present in all the affected family members. Absent in the 400 reference alleles, these mutations altered the amino acids highly conserved among various species, with the exception of p.I257L. In conclusion,
\end{abstract}

Correspondence to: Dr Jie-Fu Yang, Department of Cardiology, Beijing Hospital, 1 Dahua Road, Beijing 100730, P.R. China E-mail: jiefuyang69@sina.com

Dr Yi-Qing Yang, Department of Cardiology and Cardiovascular Research, Shanghai Chest Hospital, Shanghai Jiaotong University School of Medicine, 241 West Huaihai Road, Shanghai 200030, P.R. China

E-mail: yang99yang66@hotmail.com

Key words: arrhythmia, atrial fibrillation, genetics, gap junction channel, GJA5 this study expands the spectrum of GJA5 mutations associated with AF and provides novel insights into the molecular basis of AF, suggesting potential implications for the improved, gene-specific rhythm control strategies.

\section{Introduction}

Atrial fibrillation (AF) is the most common type of cardiac arrhythmia encountered in clinical practice, responsible for $\sim 1 / 3$ of hospitalizations for cardiac arrhythmias. This condition shows a marked increase in prevalence with advancing age, ranging from $\sim 0.4 \%$ of the whole population to $\sim 10 \%$ of the octogenarian population $(1,2)$. According to the Framingham Heart Study (3), during the lifetime of subjects $>40$ years of age, there is a $25 \%$ risk for the development of AF. The chaotic heart rhythm is not merely associated with a variety of symptoms, such as palpitations, dizziness, syncope or shortness of breath, but is also accountable for significantly increased morbidity and mortality (1). In comparison with individuals in sinus rhythm, patients with AF have a 6-fold increase in the risk of stroke, and $>15 \%$ of all strokes are ascribed to AF (4). Notably, the risk of AF-related thromboembolism also significantly increases with age, rising from $1.5 \%$ at the age of $50-59$ years to $23.5 \%$ at the age of $80-89$ years (4). The incidence of death is estimated to have doubled among patients with AF compared with individuals with normal heart rhythm (5). AF also contributes to degraded quality of life, compromised exercise performance, impaired cognitive function or dementia, tachycardia-induced cardiomyopathy, and left ventricular dysfunction or even congestive heart failure, inflicting a large economic burden on the National Healthcare Systems worldwide (6). Despite the significant prevalence and therapeutic challenge, the molecular mechanisms involved in the pathogenesis of AF remain poorly understood.

Traditionally, AF has been considered as a complication derived from miscellaneous adverse cardiac or systemic conditions, including hypertension, coronary artery disease, rheumatic heart disease, valvular heart disease, pulmonary heart disease, cardiomyopathy, cardiac surgery, pericarditis, congestive heart failure, type 2 diabetes mellitus, obstructive sleep apnea, hyperthyroidism and electrolyte imbalance (1,6-10). However, in 30-45\% of AF patients, no underlying causes are identified by routine procedures, where AF is termed 
'idiopathic' or 'lone' (1), and $\geq 15 \%$ of AF patients have a positive family history, a condition defined as familial AF (11). Mounting evidence has substantiated the familial aggregation of AF and enhanced susceptibility to AF in the close relatives of patients with $\mathrm{AF}$, suggesting an important genetic basis for $\mathrm{AF}$ (12-18). Genome-wide linkage analyses with polymorphic microsatellite markers mapped susceptibility loci for AF on human chromosomes 10q22, 6q14-16, 11p15.5, 5p13 and 5p15, of which AF-causing mutations in 2 genes, including $K C N Q 1$ on chromosome 11p15.5 and NUP155 on chromosome 5p13, were identified and functionally characterized (19-24). Genetic scan of candidate genes unveiled a long list of AF-associated genes, including KCNE2, KCNE3, KCNE5, KCNH2, KCNJ2, KCNJ8, KCNA5, SCN5A, NPPA, GATA4, GATA5 and GATA6 (25-41). Nevertheless, AF is a genetically heterogeneous disorder and the genetic determinants for $\mathrm{AF}$ in the majority of patients remain to be identified (11).

A previous study has underscored the essential roles of gap junction channels in heart electrophysiology, particularly in cardiac action potential propagation (42). Gap junctions are intercellular channels responsible for the exchange of ions and small molecules between adjacent cells. The functional gap junction channel is composed of two hemichannels, known as connexons, one provided by each cell. Connexons are hexamers of membrane-spanning proteins called connexins. At present, $>20$ connexin genes have been identified in mouse and human (43). In the human heart, myocardial gap junctions are constructed mainly by the connexin isoforms 40,43 and 45. Connexin40, also designated gap junction protein $\alpha 5$ (GJA5), is selectively expressed in the atrial myocytes, atrioventricular node, His-bundle and ventricular conduction system (Purkinje fibers), and is crucial in the electrical synchronization of the atrium and the rapid conduction of impulses in the His-Purkinje (44). In GJA5-deficient mice, spontaneous or inducible arrhythmias as well as conduction abnormalities have been observed (45). In the goat, alterations in expression levels and the distribution pattern of atrial GJA5 may constitute a cell substrate underlying susceptibility and perpetuation of AF (46). In human, cardiac GJA5 remodeling may lead to abnormal electrical coupling, forming an electrophysiological matrix with potential arrhythmogenic effect (47). By reducing GJA5 protein levels, several closely linked polymorphisms in the promoter region of the GJA5 gene have been strongly associated with enhanced atrial vulnerability and increased risk for lone AF (48-52). Furthermore, multiple somatic and germline mutations in GJA5 have been reported to underlie AF (53-55). These findings provide a rationale to scan GJA5 as a logical candidate gene for AF.

In this study, sequence analysis of the GJA5 gene was performed in a cohort of 310 unrelated patients with lone AF in contrast to a total of 200 ethnically matched, unrelated healthy individuals, in order to evaluate the prevalence and spectrum of GJA5 mutations associated with lone AF.

\section{Materials and methods}

Study subjects. A cohort of 310 unrelated patients with lone AF were included in this study from the Chinese Han population. The available relatives of the probands were also included. A total of 200 unrelated healthy individuals matched for age, gender and race were included as controls. Peripheral venous blood specimens were prepared and clinical data including medical records, electrocardiogram and echocardiography reports were collected. The study subjects were clinically classified using a consistently applied set of definitions (11). Briefly, diagnosis of AF was performed by a standard 12-lead electrocardiogram demonstrating no P-waves and irregular R-R intervals irrespective of clinical symptoms. Lone AF was defined as AF occurring in individuals $<60$ years of age without other cardiac or systemic diseases by physical examination, electrocardiogram, transthoracic echocardiogram and extensive laboratory tests. Relatives with AF occurring at any age in the setting of structural heart disease (hypertensive, ischemic, myocardial or valvular) were classified as 'undetermined' for having an inherited form of AF. The 'undetermined' classification was also used when documentation of $\mathrm{AF}$ on an electrocardiogram tracing was absent in relatives with symptoms consistent with AF (palpitations, dyspnea and light-headedness), or when a screening electrocardiogram and echocardiogram were not performed, regardless of the symptoms. Relatives were classified as 'unaffected' when they were asymptomatic and had a normal electrocardiogram. In addition, paroxysmal AF was defined as AF lasting $>30 \mathrm{sec}$ that terminated spontaneously. Persistent AF was defined as AF lasting $>7$ days and requiring either pharmacologic therapy or electrical cardioversion for termination. AF that was refractory to cardioversion or that was allowed to continue was classified as permanent (1). The study protocol was reviewed and approved by the local Institutional Ethics Committee and written informed consent was obtained from all the participants prior to investigation.

Genetic studies. Genomic DNA from the participants was extracted from blood lymphocytes with the Wizard ${ }^{\circledR}$ Genomic DNA Purification kit (Promega, Madison, WI, USA). The candidate gene GJA5 was screened in 310 unrelated patients with lone AF and genotyping of GJA5 in the relatives of mutation carriers and 200 unrelated control individuals was subsequently performed for the presence of mutations identified in index patients. The referential genomic DNA sequence of GJA5 was derived from GenBank (accession number: NG_009369). With the aid of on-line Primer3 software (http://frodo.wi.mit.edu), the primer pairs used to amplify the complete coding region and splice junctions of GJA5 by polymerase chain reaction (PCR) were designed as previously described $(54,55)$. PCR was performed using HotStar Taq DNA Polymerase (Qiagen, Hilden, Germany) on a Veriti ${ }^{\circledR}$ Thermal Cycler (Applied Biosystems, Foster, CA, USA) with standard conditions and concentrations of reagents. Amplified products were purified with the QIAquick ${ }^{\circledR}$ Gel Extraction kit (Qiagen). Both strands of each amplicon were sequenced with a BigDye ${ }^{\circledR}$ Terminator v3.1 Cycle Sequencing kit (Applied Biosystems) under an ABI PRISM 3130 XL DNA Analyzer (Applied Biosystems). Primer sequences were those previously designed for specific region amplifications. DNA sequences were viewed and analyzed with the DNA Sequencing Analysis Software v5.1 (Applied Biosystems). The sequence variant was validated by resequencing of an independent PCR-generated amplicon from the same subject and met the quality control threshold 
Table I. Clinical characteristics of the 310 unrelated patients with lone atrial fibrillation.

\begin{tabular}{lcc}
\hline Characteristics & $\begin{array}{c}\text { No. } \\
\text { or quantity }\end{array}$ & $\begin{array}{c}\text { Percentage } \\
\text { or range }\end{array}$ \\
\hline Male:female & $142: 168$ & $71: 84$ \\
Age of onset (years) & 45.2 & $18-59$ \\
Paroxysmal AF on presentation & 245 & 79 \\
Progression to permanent AF & 54 & 17.4 \\
History of cardioversion & 31 & 14 \\
History of pacemaker & 18 & 5.8 \\
Resting heart rate (bpm) & 72.5 & $50-158$ \\
Systolic blood pressure (mmHg) & 128.4 & $90-138$ \\
Diastolic blood pressure (mmHg) & 82.6 & $60-88$ \\
Body mass index (kg/m $\left.{ }^{2}\right)$ & 23.0 & $19-26$ \\
Left atrial dimension (mm) & 35 & $22-40$ \\
Left ventricular ejection fraction & 0.6 & $0.5-0.7$ \\
Fasting blood glucose (mmol/l) & 4.4 & $3.6-5.8$ \\
Total cholesterol (mmol/l) & 3.5 & $3.0-5.8$ \\
Triglycerides (mmol/l) & 1.3 & $0.5-1.7$ \\
Medications & & \\
Aspirin & 86 & 27.7 \\
Warfarin & 115 & 37.1 \\
B-blocker & 102 & 32.9 \\
Calcium channel blocker & 35 & 11.3 \\
Digoxin & 110 & 35.5 \\
\hline
\end{tabular}

with a call rate of $>99 \%$. Additionally, an identified variant was searched in the single nucleotide polymorphism (SNP) database from the National Center for Biotechnology Information (NCBI, http://www.ncbi.nlm.nih.gov/SNP) to confirm the novelty.

Alignment of multiple GJA5 protein sequences across species. The multiple GJA5 protein sequences across various species were aligned using the online program MUSCLE, version 3.6 (http://www.ncbi.nlm.nih.gov/).

Statistical analysis. Data were expressed as the means \pm standard deviation (SD). Continuous variables were tested for normality of distribution and the Student's unpaired t-test was used for comparison of numeric variables between patient and control groups. Comparison of the categorical variables between the 2 groups was performed using Pearson's $\chi^{2}$ or Fisher's exact tests when appropriate. A two-sided P-value of $<0.05$ was considered to indicate statistically significant difference.

\section{Results}

Characteristics of the study subjects. A cohort of 310 unrelated patients with lone AF were included in this study and clinically evaluated in contrast to a total of 200 matched, unrelated
A
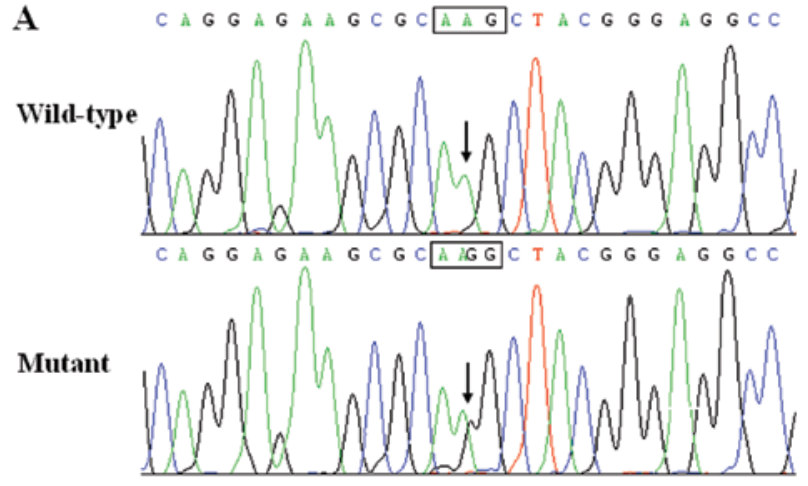

B

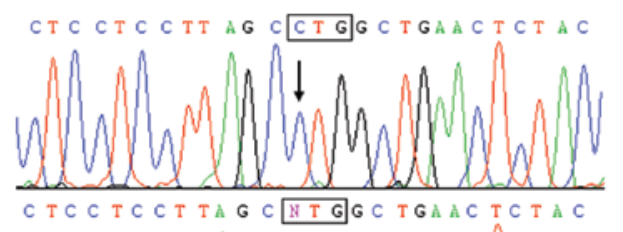

Mutant

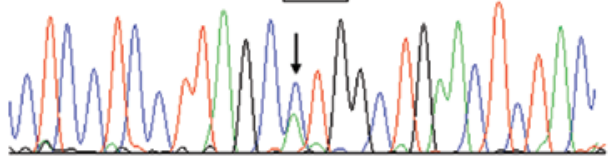

C

Wild-type

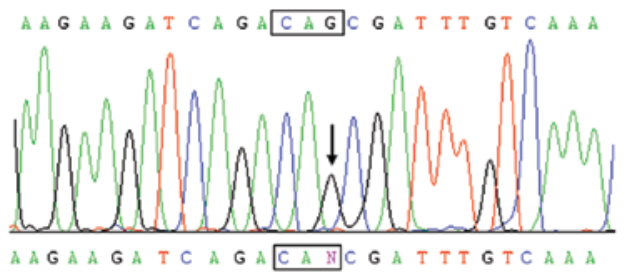

Mutant

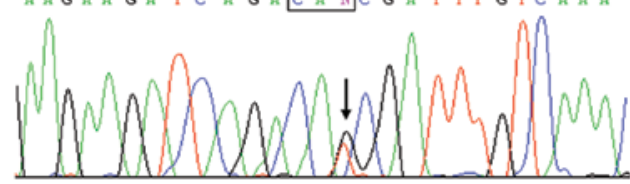

D
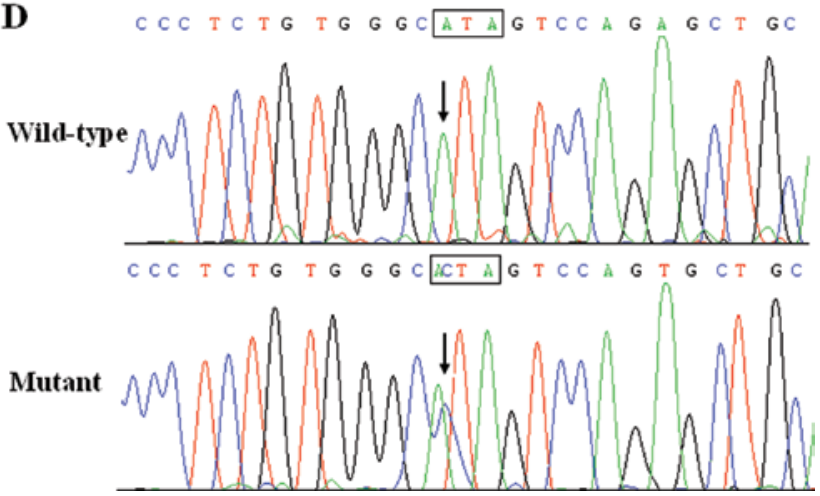

Figure 1. Sequence electropherograms of GJA5 in the probands and controls. The arrow indicates the heterozygous nucleotides of (A) A/G, (B) C/A, (C) G/T and (D) A/C, in the probands from families 1,2,3 and 4, respectively (mutant) or the homozygous nucleotides of (A) A, (B) C, (C) G and (D) A, in the corresponding controls (wild-type). The rectangle denotes the nucleotides comprising a codon of GJA5.

healthy individuals. None of the subjects had documented traditional risk factors for AF. There were no significant differences between lone AF and control groups in baseline characteristics including age, gender, body mass index, blood pressure, fasting blood glucose, serum lipid, left atrial dimension, left ventricular ejection fraction, heart rate at rest, as well as life style (data not shown). The basic clinical characteristics of the 310 patients with lone AF are summarized in Table I. 

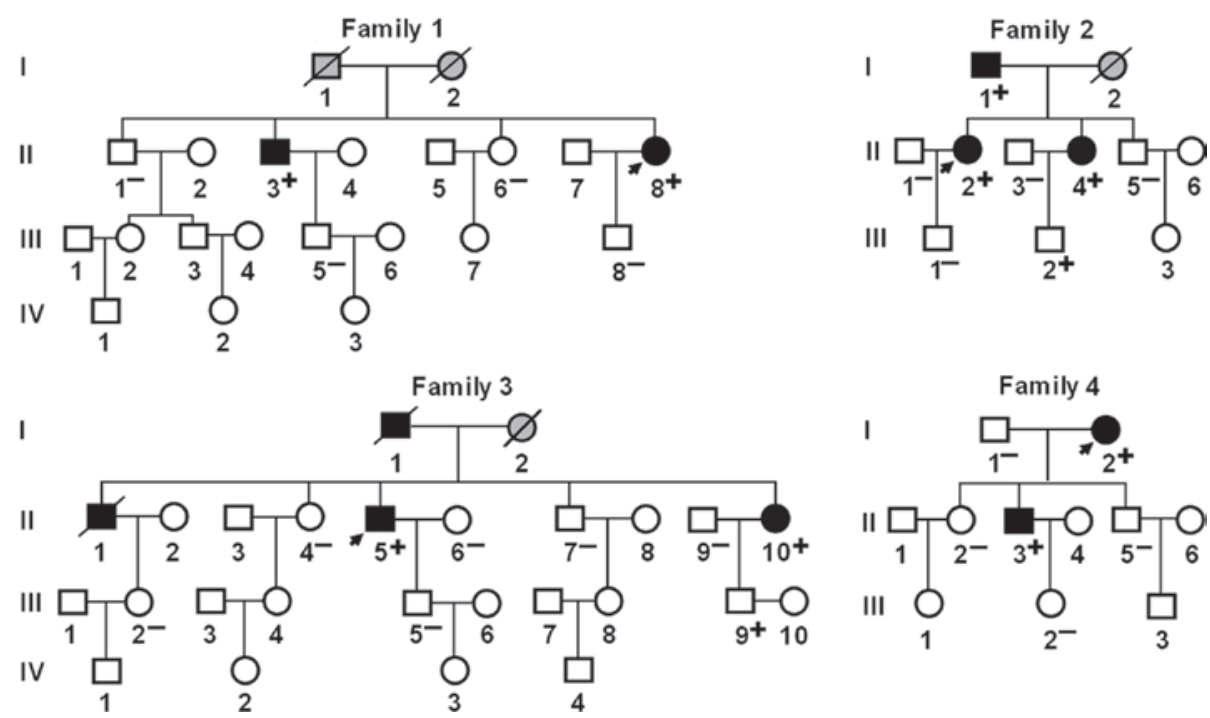

Figure 2. Pedigree structures of families with atrial fibrillation (AF). Families are designated as 1, 2, 3 and 4, respectively. Family members are identified by generations and numbers. Squares, male family members; circles, female members; symbols with a slash, the deceased members; closed symbols, affected members; open symbols, unaffected members; stippled symbols, members with phenotype undetermined; arrows, probands; '+', carriers of the heterozygous mutations; and '-', non-carriers.

GJA5 mutations. A total of 310 unrelated patients with lone AF were genetically evaluated. Direct sequencing of the entire coding region and exon-intron boundaries of the GJA5 gene was performed after PCR amplification of genomic DNA from the 310 AF patients. Four heterozygous missense mutations in GJA5 were identified in 4 of 310 unrelated index patients, respectively. The total population prevalence of GJA5 mutations based on probands was $\sim 1.29 \%$. Specifically, a substitution of guanine for adenine in the second nucleotide of codon 107 (c.320A $>\mathrm{G}$ ), predicting the transition of lysine into arginine at amino acid position 107 (p.K107R) was detected in the proband from family 1 . A replacement of cytosine by adenine in the first nucleotide of codon 223 (c.667C>A), resulting in the transversion of leucine into histidine $(\mathrm{H})$ at amino acid 223 (p.L223H) was observed in the proband from family 2 . A change of guanine into thymine in the last nucleotide of codon 236 (c.708G >T), corresponding to the displacement of glutamine by $\mathrm{H}$ at amino acid 236 (p.Q236H) was identified in the proband from family 3 . An adenine-to-cytosine conversion in the first nucleotide of codon 257 (c.769A $>$ C), equivalent to an isoleucine-to-leucine shift at amino acid 257 (p.I257L) was identified in the proband from family 4 . The sequence chromatograms showing the identified heterozygous GJA5 mutations of c.320A $>\mathrm{G}$, c.667C $>\mathrm{A}$, c.708G $>\mathrm{T}$ and c.769A $>\mathrm{C}$ in comparison to corresponding control sequences are shown in Fig. 1.

The missense mutations were not found in either the 400 control chromosomes or reported in the SNP database. Genetic scanning of the families demonstrated that in each family, the gene variant was present in all the affected living family members, while it was absent in unaffected family members examined with the exception of individuals III-2 in family 2 and III-9 in family 3 , suggesting that the long-term follow-up of asymptomatic subjects harboring the variations is needed to confirm its clinical significance. Analysis of the pedigrees showed that each mutation co-segregated with AF transmitted in an autosomal dominant pattern in the family with an incomplete penetrance. The pedigree structures of the 4 families are shown in Fig. 2. The phenotypic characteristics and results of genetic screening of the affected family members are presented in Table II.

Multiple alignments of GJA5 protein sequences across species. A cross-species alignment of GJA5 protein sequences demonstrated that the altered amino acids were highly and evolutionarily conserved with the exception of p.I257 (Fig. 3).

\section{Discussion}

In the present study, four novel heterozygous GJA5 mutations, p.K107R, p.L223M, p.Q236H and p.I257L, were identified in four unrelated families with AF, respectively, with an estimated mutational prevalence of $1.29 \%$. In each family, the missense mutation was present in all the affected family members examined, while it was absent in the unaffected family members, with the exception of individuals III-2 in family 2 and III-9 in family 3 . These mutations were absent in 400 normal chromosomes from an ethnically-matched control population. A cross-species alignment of GJA5 protein sequences demonstrated that the altered amino acids were highly and evolutionarily conserved among species, with the exception of p.I257. Therefore, it is likely that mutated GJA5 caused or conferred susceptibility to AF in these families.

Two carriers of GJA5 mutations, including individual III-2 in family 2 who carried the p.L223M mutation and individual III-9 in family 3 who harbored the p.Q236H mutation, did not have AF during a 24-h electrocardiographic monitoring. This observation may be explained by the following reasons. Firstly, AF occurs as rarely as a few times in a lifetime for some patients with AF (56); considering the performed electrocardiographic monitoring for only $24 \mathrm{~h}$, a longer duration of monitoring may be required to record paroxysmal AF in these patients. Secondly, AF occurs more commonly in older patients; thus, these carriers may not be old enough to develop 
Table II. Phenotypic characteristics and status of GJA5 mutations of the affected pedigree members.

\begin{tabular}{|c|c|c|c|c|c|c|c|c|c|}
\hline \multicolumn{4}{|c|}{ Subject information } & \multirow{2}{*}{$\frac{\text { Phenotype }}{\text { AF }}$} & \multicolumn{2}{|c|}{ Electrocardiogram } & \multicolumn{2}{|c|}{ Echocardiogram } & \multirow{2}{*}{ 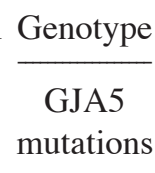 } \\
\hline Identity & Gender & $\begin{array}{l}\text { Age at time of } \\
\text { study (years) }\end{array}$ & $\begin{array}{c}\text { Age at diagnosis of } \\
\text { AF (years) }\end{array}$ & & $\begin{array}{l}\text { P-wave } \\
(\mathrm{ms})\end{array}$ & $\begin{array}{l}\text { QRS interval } \\
(\mathrm{ms})\end{array}$ & $\begin{array}{l}\mathrm{LAD} \\
(\mathrm{mm})\end{array}$ & $\begin{array}{l}\text { LVEF } \\
(\%)\end{array}$ & \\
\hline Family 1 & & & & & & & & & K107R \\
\hline II-3 & M & 56 & 50 & Paroxysmal & 100 & 98 & 30 & 70 & $+/-$ \\
\hline II-8 & F & 48 & 42 & Persistent & 106 & 92 & 30 & 65 & $+/-$ \\
\hline Family 2 & & & & & & & & & L233M \\
\hline $\mathrm{I}-1$ & M & 65 & 50 & Permanent & 98 & 94 & 38 & 62 & $+/-$ \\
\hline II-2 & F & 41 & 38 & Paroxysmal & 92 & 90 & 36 & 56 & $+/-$ \\
\hline II-4 & F & 36 & 36 & Paroxysmal & 110 & 84 & 32 & 66 & $+/-$ \\
\hline Family 3 & & & & & & & & & Q236H \\
\hline $\mathrm{I}-1$ & M & $70^{\mathrm{a}}$ & 55 & Paroxysmal & N/A & 90 & N/A & N/A & N/A \\
\hline II-1 & $\mathrm{M}$ & $64^{\mathrm{a}}$ & 53 & Paroxysmal & N/A & 92 & N/A & N/A & N/A \\
\hline II-5 & $\mathrm{M}$ & 60 & 58 & Paroxysmal & 114 & $114 .$. & 38 & 64 & $+/-$ \\
\hline II-10 & F & 54 & 54 & Paroxysmal & 92 & 88 & 32 & 60 & $+/-$ \\
\hline Family 4 & & & & & & & & & $\mathrm{I} 257 \mathrm{~L}$ \\
\hline $\mathrm{I}-2$ & F & 64 & 45 & Paroxysmal & 102 & 90 & 36 & 65 & $+/-$ \\
\hline II-3 & M & 42 & 40 & Paroxysmal & 112 & 92 & 33 & 67 & $+/-$ \\
\hline
\end{tabular}

${ }^{\mathrm{a}} \mathrm{Age}$ at death. AF, atrial fibrillation; LAD, left atrial dimension; LVEF, left ventricular ejection fraction; M, male; F, female; +, presence of mutation; -, absence of mutation; N/A, not available or not applicable.

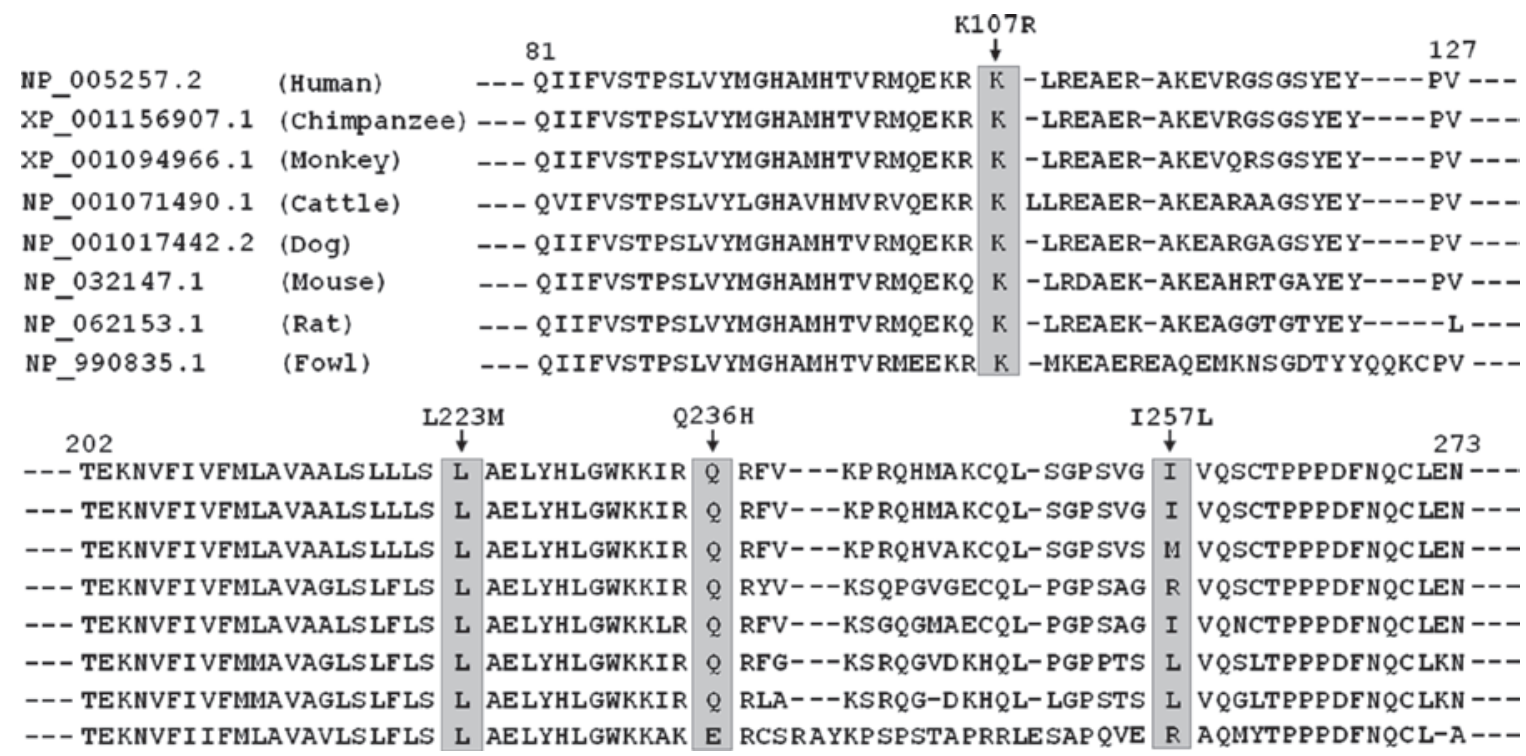

Figure 3. Multiple alignments of GJA5 protein sequences across species. The altered amino acids of p.K107, p.L223 and p.Q236 are highly and evolutionarily conserved among species.

the disease. Thirdly, familial AF caused by the mutation p.L223M or p.Q236H may have a low or incomplete penetration. Additionally, p.L223M or p.Q236H may be only a genetic risk factor predisposing to AF, rather than a direct cause of $\mathrm{AF}$, and environmental risk factors may be required for the onset of AF.

Multiple GJA5 mutations or polymorphisms have been previously involved in AF (48-55). Similar to the present findings, Yang et al $(54,55)$ have previously performed a sequence analysis of the GJA5 gene in a total of 344 index patients with lone AF, and identified four novel heterozygous missense mutations (p.Q49X, p.V85I, p.L221I and p.L229M), with a mutational prevalence of $\sim 1.16 \%$. Gollob et al (53) performed the first scan of GJA5 in patients with lone AF and identified four novel heterozygous missense mutations in 4 of 15 AF patients, of which 3 mutations (p.G38D, p.P88S and p.M163V) were found in the cardiac-tissue specimens but not in the peripheral lymphocytes; one mutation (p.A96S) was detected in both cardiac tissue and lymphocytes, with a germline mutational prevalence of $\sim 6.67 \%$. The p.A96S 
variant was absent in the patient's 3 siblings and wife, while it was present in the patient's 2 sons without history of AF and in 1 of 120 controls. Functional analysis of mutant GJA5 proteins demonstrated impaired intracellular transport or reduced intercellular electrical coupling (53). By sequencing the 5 ' untranslated exon and the proximal promoter region of the GJA5 gene (GenBank accession no. AF246295) in patients with familial atrial standstill, Groenewegen et al (48) found two closely linked polymorphisms, of which one was a $\mathrm{G}$ to $\mathrm{A}$ transition at 44 nucleotides upstream of the transcription start site $(-44 \mathrm{G}>\mathrm{A})$, and the other was a substitution of $\mathrm{G}$ for $\mathrm{A}$ in exon 1 at 71 nucleotides downstream of the transcription start site $(+71 \mathrm{~A}>\mathrm{G})$. Luciferase reporter gene assays of the minor GJA5 haplotype $(-44 \mathrm{~A},+71 \mathrm{G})$ in GJA5-expressing rat arterial smooth muscular cells showed a $>2$-fold decrease in promoter activity compared with the more common haplotype $(-44 \mathrm{G}$, +71A). The reduced GJA5 expression may lead to a reduction of the total amount of GJA5 protein in vivo, providing an atrial electrophysiological substrate favoring arrhythmia (48). Furthermore, the GJA5 polymorphisms have been strongly associated with increased spatial dispersion of refractoriness as a marker for enhanced atrial vulnerability and carriers of the -44AA genotype had a significantly higher risk of AF compared with those carrying the -44GG genotype (49). In a larger case-control study, the rare haplotype frequency of GJA5 $(-44 \mathrm{~A},+71 \mathrm{G})$ was statistically higher in the AF compared with the control group, and also functional studies using luciferase as the reporter have demonstrated that GJA5 $(-44 \mathrm{~A},+71 \mathrm{G})$ had significantly lower promoter activity compared with GJA5 (-44G, +71A) in atrial myocytes from mice (50). A novel common GJA5 gene promoter variant has recently been associated with reduced GJA5 expression in human atria and increased vulnerability to AF (51). These results highlight the pivotal role of GJA5 for atrial electrophysiology and indicate that dysfunctional GJA5 may be an important molecular mechanism involved in the pathogenesis of AF.

The association of abnormal GJA5 with enhanced susceptibility to arrhythmias has been substantiated in animal models. Targeted gene deletion of GJA5 in mice produced multiple abnormalities including increased sinoatrial node recovery time, decreased conduction velocity of atria, atrioventricular node and bundle branch, and impaired sinoatrial propagation with atrial ectopic pacemakers, which developed an arrhythmogenic substrate prone to $\mathrm{AF}(57,58)$. In a canine sterile pericarditis model, the gap junction conduction-enhancing antiarrhythmic peptide, Gap-134, improved conduction and reduced AF (59). Similarly, in a dog model of AF due to myocardial ischemia, administration of ZP123, a gap junction conductance-improving modifier, prevented ischemia-induced conduction slowing and reduced AF duration (60). Notably, in experimental swine, gene therapy with adenovirus expressing GJA5 improved cardiac conduction and reduced AF, demonstrating the viability of gene therapy for the prevention of atrial arrhythmias (61).

It is well known that AF is a complex arrhythmia ascribed to multiple possible mechanisms. Despite the presence of an inherited defect, a favorable substrate for AF, within the myocardial tissue of affected patients from birth, the onset of genetically-based AF often requires a trigger for initiation, presumably by exacerbating the already anomalous cardiac cellular electrophysiology in the existence of mutant protein. One of the most common triggers is the increased vagal tone mediated by muscarinic receptors, causing uneven shortening of refractoriness in the atria and, thus, electrophysiological heterogeneity (62). The stimulation of muscarinic receptors has been shown to impair the cell-cell coupling mediated by gap junctions (63). Together with the data mentioned above, this experimental result suggests a potential pathogenic link between increased cardiac parasympathetic nerve activity, impaired myocardial intercellular electrical coupling, and the occurrence of AF.

Notably, GJA5 is an important determinant for impulse propagation in the atrium as well as the specialized conduction system and abnormal expression of GJA5 predisposes to AF. However, functional changes in GJA5 alone may not be sufficient for significantly prolonged P-wave duration, PQ interval, QRS duration and QT duration in the surface electrocardiogram, as observed in these AF families and other AF patients (48-55). Additionally, full deficiency for GJA5 has been associated with altered electrocardiographic parameters in GJA5 knockout mice, in contrast to haploinsufficiency for GJA5 (57). These findings suggest that additional factors combined with reduced coupling lead to AF.

In conclusion, the present investigation links novel GJA5 mutations to $\mathrm{AF}$, which provides novel insight into the molecular mechanisms associated with the arrhythmogenesis and ultimately may result in improved, patient-specific rhythm control strategies.

\section{Acknowledgements}

The authors are greatly indebted to participants for their dedication to the study. This study was supported by grants from the National Natural Science Foundation of China (nos. 81070153, 81270161 and 30570768), the Natural Science Foundation of Shanghai, China (10ZR1428000), the Personnel Development Foundation of Shanghai, China (no. 2010019), and the Key Program of Basic Research of Shanghai, China (nos. 10JC1414000, 10JC1414001 and 10JC1414002).

\section{References}

1. Fuster V, Rydén LE, Cannom DS, Crijns HJ, Curtis AB, Ellenbogen KA, Halperin JL, Kay GN, Le Huezey JY, Lowe JE, Olsson SB, Prystowsky EN, Tamargo JL, Wann LS, Smith SC Jr, PrioriSG, Estes NA III, Ezekowitz MD, Jackman WM, January CT, Lowe JE, Page RL, Slotwiner DJ, Stevenson WG, Tracy CM, Jacobs AK, Anderson JL, Albert N, Buller CE, Creager MA, Ettinger SM, Guyton RA, Halperin JL, Hochman JS, Kushner FG, Ohman EM, Stevenson WG, Tarkington LG and Yancy CW; American College of Cardiology Foundation/American Heart Association Task Force: 2011 ACCF/AHA/HRS focused updates incorporated into the ACC/AHA/ESC 2006 guidelines for the management of patients with atrial fibrillation: a report of the American College of Cardiology Foundation/American Heart Association Task Force on practice guidelines. Circulation 123: e269-e367, 2011.

2. Go AS, Hylek EM, Phillips KA, Chang Y, Henault LE, Selby JV and Singer DE: Prevalence of diagnosed atrial fibrillation in adults: national implications for rhythm management and stroke prevention: the AnTicoagulation and Risk Factors in Atrial Fibrillation (ATRIA) Study. JAMA 285: 2370-2375, 2001.

3. Lloyd-Jones DM, Wang TJ, Leip EP, Larson MG, Levy D, Vasan RS, D'Agostino RB, Massaro JM, Beiser A, Wolf PA and Benjamin EJ: Lifetime risk for development of atrial fibrillation: the Framingham Heart Study. Circulation 110: 1042-1046, 2004. 
4. Wolf PA, Abbott RD and Kannel WB: Atrial fibrillation as an independent risk factor for stroke: the Framingham Study. Stroke 22: 983-988, 1991.

5. Benjamin EJ, Wolf PA, D'Agostino RB, Silbershatz H, Kannel WB and Levy D: Impact of atrial fibrillation on the risk of death: the Framingham Heart Study. Circulation 98: 946-952, 1998.

6. Nattel S: New ideas about atrial fibrillation 50 years on Nature 415: 219-226, 2002.

7. Huang WJ, Zhou R, Zeng XR, Tan XQ, Cheng ZH, Tang MH, Gou LT, Chen LJ, Tong AP, He Y and Yang JL: Comparative proteomic analysis of atrial appendages from rheumatic heart disease patients with sinus rhythm and atrial fibrillation. Mol Med Rep 4: 655-661, 2011.

8. Li H, Li S, Yu B and Liu S: Expression of miR-133 and miR-30 in chronic atrial fibrillation in canines. Mol Med Rep 5: 1457-1460, 2012.

9. Cheng T, Wang XF, Hou YT and Zhang L: Correlation between atrial fibrillation, serum amyloid protein $\mathrm{A}$ and other inflammatory cytokines. Mol Med Rep 6: 581-584, 2012.

10. Kim SM, Lee JH, Kim JR, Shin DG, Lee SH and Cho KH: Female patients with atrial fibrillation have increased oxidized and glycated lipoprotein properties and lower apolipoprotein A-I expression in HDL. Int J Mol Med 27: 841-849, 2011.

11. Darbar D, Herron KJ, Ballew JD, Jahangir A, Gersh BJ, Shen WK, Hammill SC, Packer DL and Olson TM: Familial atrial fibrillation is a genetically heterogeneous disorder. J Am Coll Cardiol 41: 2185-2192, 2003.

12. Fox CS, Parise H, D'Agostino RB Sr, Lloyd-Jones DM, Vasan RS Wang TJ, Levy D, Wolf PA and Benjamin EJ: Parental atrial fibrillation as a risk factor for atrial fibrillation in offspring. JAMA 291: 2851-2855, 2004.

13. Ellinor PT, Yoerger DM, Ruskin JN and MacRae CA: Familial aggregation in lone atrial fibrillation. Hum Genet 118: 179-184, 2005.

14. Arnar DO, Thorvaldsson S, Manolio TA, Thorgeirsson G Kristjansson K, Hakonarson H and Stefansson K: Familia aggregation of atrial fibrillation in Iceland. Eur Heart $\mathbf{J} 27$ : 708-712, 2006

15. Junttila MJ, Raatikainen MJ, Perkiömäki JS, Hong K, Brugada R and Huikuri HV: Familial clustering of lone atrial fibrillation in patients with saddleback-type ST-segment elevation in right precordial leads. Eur Heart J 28: 463-468, 2007.

16. Christophersen IE, Ravn LS, Budtz-Joergensen E, Skytthe A, Haunsoe S, Svendsen JH and Christensen K: Familial aggregation of atrial fibrillation: a study in Danish twins. Circ Arrhythm Electrophysiol 2: 378-383, 2009.

17. Yang YQ, Zhang XL, Wang XH, Tan HW, Shi HF, Fang WY and Liu X: Familial aggregation of lone atrial fibrillation in the Chinese population. Intern Med 49: 2385-2391, 2010.

18. Lubitz SA, Yin X, Fontes JD, Magnani JW, Rienstra M, Pai M, Villalon ML, Vasan RS, Pencina MJ, Levy D, Larson MG, Ellinor PT and Benjamin EJ: Association between familial atrial fibrillation and risk of new-onset atrial fibrillation. JAMA 304 2263-2269, 2010.

19. Brugada R, Tapscott T, Czernuszewicz GZ, Marian AJ, Iglesias A Mont L, Brugada J, Girona J, Domingo A, Bachinski LL and Roberts R: Identification of a genetic locus for familial atrial fibrillation. N Engl J Med 336: 905-911, 1997.

20. Ellinor PT, Shin JT, Moore RK, Yoerger DM and MacRae CA: Locus for atrial fibrillation maps to chromosome 6q14-16. Circulation 107: 2880-2883, 2003.

21. Chen YH, Xu SJ, Bendahhou S, Wang XL, Wang Y, Xu WY, Jin HW, Sun H, Su XY, Zhuang QN, Yang YQ, Li YB, Liu Y, Xu HJ, Li XF, Ma N, Mou CP, Chen Z, Barhanin J and Huang W: KCNQ1 gain-of-function mutation in familial atrial fibrillation. Science 299: 251-254, 2003.

22. Oberti C, Wang L, Li L, Dong J, Rao S, Du W and Wang Q: Genome-wide linkage scan identifies a novel genetic locus on chromosome $5 \mathrm{p} 13$ for neonatal atrial fibrillation associated with sudden death and variable cardiomyopathy. Circulation 110 3753-3759, 2004.

23. Darbar D, Hardy A, Haines JL and Roden DM: Prolonged signal-averaged $\mathrm{P}$-wave duration as an intermediate phenotype for familial atrial fibrillation. J Am Coll Cardiol 51: 1083-1089, 2008

24. Zhang X, Chen S, Yoo S, Chakrabarti S, Zhang T, Ke T, Oberti C, Yong SL, Fang F, Li L, de la Fuente R, Wang L, Chen Q and Wang QK: Mutation in nuclear pore component NUP155 leads to atrial fibrillation and early sudden cardiac death. Cell 135: 1017-1027, 2008
25. Yang Y, Xia M, Jin Q, Bendahhou S, Shi J, Chen Y, Liang B, Lin J, Liu Y, Liu B, Zhou Q, Zhang D, Wang R, Ma N, Su X, Niu K, Pei Y, Xu W, Chen Z, Wan H, Cui J, Barhanin J and Chen Y: Identification of a KCNE2 gain-of-function mutation in patients with familial atrial fibrillation. Am J Hum Genet 75: 899-905, 2004

26. Lundby A, Ravn LS, Svendsen JH, Hauns S, Olesen SP and Schmitt N: KCNE3 mutation V17M identified in a patient with lone atrial fibrillation. Cell Physiol Biochem 21: 47-54, 2008.

27. Ravn LS, Aizawa Y, Pollevick GD, Hofman-Bang J, Cordeiro JM, Dixen U, Jensen G, Wu Y, Burashnikov E, Haunso S, Guerchicoff A, Hu D, Svendsen JH, Christiansen $\mathrm{M}$ and Antzelevitch C: Gain of function in IKs secondary to a mutation in KCNE5 associated with atrial fibrillation. Heart Rhythm 5: 427-435, 2008.

28. Hong K, Bjerregaard P, Gussak I and Brugada R: Short QT syndrome and atrial fibrillation caused by mutation in KCNH2. J Cardiovasc Electrophysiol 16: 394-396, 2005.

29. Xia M, Jin Q, Bendahhou S, He Y, Larroque MM, Chen Y, Zhou Q, Yang Y, Liu Y, Liu B, Zhu Q, Zhou Y, Lin J, Liang B, Li L, Dong X, Pan Z, Wang R, Wan H, Qiu W, Xu W, Eurlings P, Barhanin J and Chen Y: A Kir2.1 gain-of-function mutation underlies familial atrial fibrillation. Biochem Biophys Res Commun 332: 1012-1019, 2005

30. Delaney JT, Muhammad R, Blair MA, Kor K, Fish FA, Roden DM and Darbar D: A KCNJ8 mutation associated with early repolarization and atrial fibrillation. Europace 14: 1428-1432, 2012.

31. Olson TM, Alekseev AE, Liu XK, Park S, Zingman LV, Bienengraeber M, Sattiraju S, Ballew JD, Jahangir A and Terzic A: Kv1.5 channelopathy due to KCNA5 loss-of-function mutation causes human atrial fibrillation. Hum Mol Genet 15: 2185-2191, 2006

32. Yang Y, Li J, Lin X, Yang Y, Hong K, Wang L, Liu J, Li L, Yan D, Liang D, Xiao J, Jin $\mathrm{H}$, Wu J, Zhang Y and Chen YH: Novel KCNA5 loss-of-function mutations responsible for atrial fibrillation. J Hum Genet 54: 277-283, 2009.

33. Darbar D, Kannankeril PJ, Donahue BS, Kucera G, Stubblefield T, Haines JL, George AL Jr and Roden DM: Cardiac sodium channel (SCN5A) variants associated with atrial fibrillation. Circulation 117: 1927-1935, 2008.

34. Hodgson-Zingman DM, Karst ML, Zingman LV, Heublein DM, Darbar D, Herron KJ, Ballew JD, de Andrade M, Burnett JC Jr and Olson TM: Atrial natriuretic peptide frameshift mutation in familial atrial fibrillation. N Engl J Med 359: 158-165, 2008.

35. Jiang JQ, Shen FF, Fang WY, Liu X and Yang YQ: Novel GATA4 mutations in lone atrial fibrillation. Int J Mol Med 28: 1025-1032, 2011.

36. Yang YQ, Wang MY, Zhang XL, Tan HW, Shi HF, Jiang WF, Wang XH, Fang WY and Liu X: GATA4 loss-of-function mutations in familial atrial fibrillation. Clin Chim Acta 412: 1825-1830, 2011.

37. Wang J, Sun YM and Yang YQ: Mutation spectrum of the GATA4 gene in patients with idiopathic atrial fibrillation. Mol Biol Rep 39: 8127-8135, 2012

38. Yang YQ, Wang J, Wang XH, Wang Q, Tan HW, Zhang M, Shen FF, Jiang JQ, Fang WY and Liu X: Mutational spectrum of the GATA5 gene associated with familial atrial fibrillation. Int J Cardiol 157: 305-307, 2012.

39. Yang YQ, Wang XH, Tan HW, Jiang WF, Fang WY and Liu X: Prevalence and spectrum of GATA6 mutations associated with familial atrial fibrillation. Int J Cardiol 155: 494-496, 2012.

40. Yang YQ, Li L, Wang J, Zhang XL, Li RG, Xu YJ, Tan HW, Wang XH, Jiang JQ, Fang WY and Liu X: GATA6 loss-offunction mutation in atrial fibrillation. Eur J Med Genet 55: 520-526, 2012

41. Li J, Liu WD, Yang ZL and Yang YQ: Novel GATA6 loss-offunction mutation responsible for familial atrial fibrillation. Int J Mol Med 4: 783-790, 2012

42. Delmar M and Makita N: Cardiac connexins, mutations and arrhythmias. Curr Opin Cardiol 27: 236-241, 2012.

43. Jansen JA, van Veen TA, de Bakker JM and van Rijen HV Cardiac connexins and impulse propagation. J Mol Cell Cardiol 48: 76-82, 2010

44. Vozzi C, Dupont E, Coppen SR, Yeh HI and Severs NJ: Chamberrelated differences in connexin expression in the human heart. J Mol Cell Cardiol 31: 991-1003, 1999.

45. Hagendorff A, Schumacher B, Kirchhoff S, Lüderitz B and Willecke K: Conduction disturbances and increased atrial vulnerability in Connexin40-deficient mice analyzed by transesophageal stimulation. Circulation 99: 1508-1515, 1999. 
46. van der Velden HM, Ausma J, Rook MB, Hellemons AJ, van Veen TA, Allessie MA and Jongsma HJ: Gap junctional remodeling in relation to stabilization of atrial fibrillation in the goat. Cardiovasc Res 46: 476-486, 2000.

47. Severs NJ, Coppen SR, Dupont E, Yeh HI, Ko YS and Matsushita T: Gap junction alterations in human cardiac disease. Cardiovasc Res 62: 368-377, 2004.

48. Groenewegen WA, Firouzi M, Bezzina CR, Vliex S, van Langen IM, Sandkuijl L, Smits JP, Hulsbeek M, Rook MB, Jongsma HJ and Wilde AA: A cardiac sodium channel mutation cosegregates with a rare connexin 40 genotype in familial atrial standstill. Circ Res 92: 14-22, 2003.

49. Firouzi M, Ramanna H, Kok B, Jongsma HJ, Koeleman BP, Doevendans PA, Groenewegen WA and Hauer RN: Association of human connexin40 gene polymorphisms with atrial vulnerability as a risk factor for lone atrial fibrillation. Circ Res 95: e29-e33, 2004.

50. Juang JM, Chern YR, Tsai CT, Chiang FT, Lin JL, Hwang JJ, Hsu KL, Tseng CD, Tseng YZ and Lai LP: The association of human connexin 40 genetic polymorphisms with atrial fibrillation. Int J Cardiol 116: 107-112, 2007.

51. Wirka RC, Gore S, Van Wagoner DR, Arking DE, Lubitz SA, Lunetta KL, Benjamin EJ, Alonso A, Ellinor PT, Barnard J, Chung MK and Smith JD: A common connexin-40 gene promoter variant affects connexin-40 expression in human atria and is associated with atrial fibrillation. Circ Arrhythm Electrophysiol 4: 87-93, 2011.

52. Chaldoupi SM, Hubens LE, Smit Duijzentkunst DA, van Stuijvenberg L, Bierhuizen MF, van Aarnhem EE, Nelen M, de Bakker JM, Hauer RN, van Rijen HV, Loh P and van Veen TA: Reduced connexin40 protein expression in the right atrial appendage of patients bearing the minor connexin40 allele $(-44 \mathrm{G} \rightarrow \mathrm{A})$. Europace 14: 1199-1205, 2012.

53. Gollob MH, Jones DL, Krahn AD, Danis L, Gong XQ, Shao Q, Liu X, Veinot JP, Tang AS, Stewart AF, Tesson F, Klein GJ, Yee R, Skanes AC, Guiraudon GM, Ebihara L and Bai D: Somatic mutations in the connexin 40 gene (GJA5) in atrial fibrillation. N Engl J Med 354: 2677-2688, 2006.

54. Yang YQ, Zhang XL, Wang XH, Tan HW, Shi HF, Jiang WF, Fang WY and Liu X: Connexin40 nonsense mutation in familial atrial fibrillation. Int J Mol Med 26: 605-610, 2010.
55. Yang YQ, Liu X, Zhang XL, Wang XH, Tan HW, Shi HF, Jiang WF and Fang WY: Novel connexin40 missense mutations in patients with familial atrial fibrillation. Europace 12: 1421-1427, 2010.

56. Chugh SS, Blackshear JL, Shen WK, Hammill SC and Gersh BJ: Epidemiology and natural history of atrial fibrillation: clinical implications. J Am Coll Cardiol 37: 371-378, 2001.

57. Chaldoupi SM, Loh P, Hauer RN, de Bakker JM and van Rijen HV: The role of connexin40 in atrial fibrillation. Cardiovasc Res 84: 15-23, 2009.

58. Bagwe S, Berenfeld O, Vaidya D, Morley GE and Jalife J: Altered right atrial excitation and propagation in connexin40 knockout mice. Circulation 112: 2245-2253, 2005

59. Rossman EI, Liu K, Morgan GA, Swillo RE, Krueger JA, Gardell SJ, Butera J, Gruver M, Kantrowitz J, Feldman HS, Petersen JS, Haugan K and Hennan JK: The gap junction modifier, GAP-134, improves conduction and reduces atrial fibrillation/ flutter in the canine sterile pericarditis model. J Pharmacol Exp Ther 329: 1127-1133, 2009.

60. Shiroshita-Takeshita A, Sakabe M, Haugan K, Hennan JK and Nattel S: Model-dependent effects of the gap junction conduction-enhancing antiarrhythmic peptide rotigaptide (ZP123) on experimental atrial fibrillation in dogs. Circulation 115 : 310-318, 2007.

61. Igarashi T, Finet JE, Takeuchi A, Fujino Y, Strom M, Greener ID, Rosenbaum DS and Donahue JK: Connexin gene transfer preserves conduction velocity and prevents atrial fibrillation. Circulation 125: 216-225, 2012.

62. Zipes DP, Mihalick MJ and Robbins FT: Effects of selective vagal stellate ganglion stimulation on atrial refractoriness. Cardiovasc Res 8: 647-655, 1974.

63. Fritz S, Kunz L, Dimitrijevic N, Grunert R, Heiss C and Mayerhofer A: Muscarinic receptors in human luteinized granulosa cells: activation blocks gap junctions and induces the transcription factor early growth response factor-1. J Clin Endocrinol Metab 87: 1362-1367, 2002. 